\title{
Literatura y competencia comunicativa: ¿Matrimonio mal avenido?'
}

Ximena Troncoso Araos"

\section{Resumen}

Este artículo aborda la relación problemática entre enseñanza de la literatura y enfoque comunicacional, específicamente, entre aprender literatura y desarrollar la competencia comunicativa. A partir de esta tensión diagnosticada, surgen las preguntas: ¿es plausible enseñar literatura desarrollando a la vez competencias comunicativas?, ¿es compatible la literatura con un enfoque comunicativo? Estas interrogantes consideran una premisa: entender la literatura como dominio con características diferenciales. Luego, se somete a prueba, desde una perspectiva literaria y didáctica, la hipótesis que es posible desarrollar competencia comunicativa sin descuidar la especificidad y potencialidad de la literatura. Para ello, se analizan diversos textos en relación con cuatro subcompetencias: léxicosemántica, textual, discursiva y sociocognitiva. Si bien una misma obra podría analizarse en función de todas estas subcompetencias, se consideran por separado para efectos de la investigación. El análisis contempla textos principalmente narrativos y algunos líricos, sin distinción de edad. Esto evidencia que es factible desarrollar las subcompetencias en distintos niveles educacionales, aunque regulando la pertinencia de los textos y el tratamiento didáctico. En términos globales, se concluye que es posible compatibilizar competencia comunicativa y literatura considerando los énfasis específicos de lo literario y sus consecuentes derivaciones didácticas.

\section{Palabras claves}

Didáctica de la literatura - Competencias comunicativas - Enfoque comunicativo.
I- Este artículo amplía las ponencias homónimas presentadas en el VI Congreso Internacional de la Cátedra UNESCO de Lectura y la Escritura, 2011, Universidad del Norte, Barranquilla, Colombia, y en el |l Congreso Nacional de Pedagogía, 2012, Universidad del Bío Bío, Chillán, Chile.

II- Universidad Católica del Maule, Talca, Chile. Contactos: xtroncos@ucm.cl; xitrona@yahoo.com 


\section{Literature and communicative competence: a wrong assorted matrimony?}

Ximena Troncoso Araos"

I- This article spreads out the homonymous papers presented at the VI International Congress of the UNESCO Chair in Reading and Writing, 2011, Universidad del Norte, Barranquilla, Colombia, and at the Second National Congress of Education, 2012, Universidad del Bío Bío, Chillán, Chile.

II- Universidad Católica del Maule, Talca, Chile. Contacts: xtroncos@ucm.cl; xitrona@yahoo.com

\begin{abstract}
This article addresses the problematic relationship between teaching literature and communicative approach, specifically between learning literature and developing communicative competence. From this diagnosed tension, the following questions arise: Is it plausible to teach literature while developing communication skills?; is literature compatible with a communicative approach? These questions consider a premise: understanding literature as a domain with different characteristics. Therefore, from a literary and educational perspective, I have tested the working hypothesis that it is possible to develop communicative competence without neglecting the specificity and potential of literature. To this end, various texts are analyzed in relation to lexical-semantic, textual, discursive, socio-cognitive and cultural sub-competencies. While a single work could be analyzed in terms of all these sub competencies, they are considered separately for the purposes of research. The analysis includes mainly narrative and some lyrical texts, regardless of age. This reveals that it is feasible to develop sub competencies at different educational levels, although adjusting the relevance of texts and didactic treatment. At the end, it is concluded that it is possible to combine communicative competence and literature considering the specific emphasis of the literary and its consequent didactic derivations.
\end{abstract}

\section{Keywords}

Teaching ofliterature-Communicative competence-Communicative approach. 


\section{La literatura en el currículo escolar}

El actual currículo escolar chileno en Lenguaje y Comunicación se caracteriza por la presencia del enfoque comunicativo (MINEDUC, 2009, 2012), adoptado a partir de la reforma educacional chilena, iniciada en 1990 y con variaciones a lo largo del tiempo ${ }^{1}$. Desde este enfoque, interesa que los alumnos desarrollen competencia comunicativa, lo que ya plantea una interrogante con respecto al lugar que cabe a la literatura en esta propuesta. Si bien la literatura está presente, el asunto problemático es de qué manera lo está. Se transita desde una enseñanza de la literatura como contenido a un saber relacionarse con la literatura, atendiendo a habilidades lectoras y también de escritura. La idea, en general, es admisible si pensamos en los saberes pertinentes para la educación escolar, especialmente a la Educación Básica.

Sin embargo, las preguntas que surgen son, por una parte, si el currículo apunta efectivamente a ello y, por otra, si un enfoque absoluto es conveniente. A lo anterior se añade una complicación conceptual: las llamadas competencias del currículo nacional corresponden a las macrohabilidades lingüísticas: hablar, escuchar, leer y escribir, las que difieren de la competencia comunicativa formulada por los estudios en las distintas taxonomías.

Bajo el enfoque comunicacional, la práctica de la lectura ha ganado mayor presencia, especialmente en Educación Básica, y se han superado visiones didácticas restrictivamente historicistas y estructuralistas. Sin embargo, no se ha ganado suficiente presencia desde la especificidad de lo literario. Más bien ha tendido a diluirse entre competencias más genéricas. Esto hace pertinente los cuestionamientos con respecto a la aplicación de este enfoque en la enseñanza.

1- Se distinguen tres etapas: prerreforma (1990 a 1995); implantación y aplicación (1996 a 2000) y consolidación (DONOSO, 2005), la que ha enfrentado serias críticas de los especialistas y, sobre todo, del movimiento estudiantil: Revolución Pingüina de secundarios seguida de la movilización universitaria.
Como señala Teresa Colomer (2010), el diseño curricular con enfoque comunicativo, en España (también en Chile), no mejoró los aprendizajes en el área de literatura. El enfoque historicista derivó a un aprendizaje centrado en los mecanismos de lectura, debido al influjo de la lingüística cognitiva y la psicolingüística; en tanto, por influencia de la animación a la lectura, se enfatizó la idea de crear el gusto por leer. Pero, plantea Colomer, hubo poca o nula articulación entre ambos objetivos. Esto, agrego, a causa de que ambas propuestas provienen de distintas fuentes y se concretan en distintos contextos: la primera funciona en el aula y en el currículo escolar; en cambio, la animación lectora se concibió para ser implementada fuera del currículo y surgió como una reacción a los efectos contraproducentes de este para formar lectores asiduos.

Felipe Munita (2010), al examinar el Marco curricular y los programas de Educación Básica, identifica tres aspectos que orientan el sentido de enseñar literatura: enriquecimiento lingüístico, formación personal y desarrollo de valores éticos y estéticos. El primer aspecto se relaciona con las competencias lingüísticas. Como señala el autor, la importancia que se le atribuye a la literatura queda restringida por su función instrumental en pro de desarrollar habilidades lingüísticas. En los otros dos aspectos podemos reconocer que se incorporan nuevos aportes, como los estudios de la literatura infantil desde la psicología, la escritura creativa, y se da cierta presencia a la apreciación estética. Pero el discurso literario sigue teniendo una presencia menor comparado con lo lingüístico, los valores y las normas. En este sentido, la literatura se concibe en función de algo, con lo que la literatura no es más que un medio, un pasaje a otra cosa que es la que interesa. De esta manera, el tratamiento de la literatura en el ámbito escolar ha fluctuado y sigue fluctuando entre justificar la literatura por la literatura, sin entender qué implica, y justificarla por algo ajeno o que poco tiene que ver con ella. 


\section{Literatura y competencia comunicativa}

Hymes define competencia comunicativa como "un conjunto de habilidades y conocimientos que permiten que los hablantes de una comunidad lingüistica puedan entenderse en las diversas situaciones de comunicación" (apud PILLEUX, 2001). Hymes (1972) retoma los conceptos de competence $y$ performance, de Chomsky, y señala la importancia de construir la teoría en relación con la práctica, de ahí la necesaria interrelación entre el conocimiento que subyace al uso de una lengua y el uso mismo, en donde lo sociolingüístico adquiere importancia.

A partir de Hymes y del aporte de otras disciplinas, Pilleux (2001) organiza las competencias agrupándolas en cuatro tipos: a) lingüistica: morfología, sintaxis, fonética, fonología y semántica; b) sociolingüística: reglas de interacción social, modelo speaking de Hymes; c) pragmática: funcional, implicaturas, presuposición; y d) psicolingüística: personalidad, sociocognición, condicionamiento afectivo. Sería precisamente el dominio de estas estructuras y funciones lo que constituye nuestro conocimiento de la lengua.

Algunos se inclinan por la idea de que la literatura no sirve para desarrollar competencia comunicativa, porque se aparta de los textos cuya función es comunicar y sus reglas de construcción son distintas: la literatura entendida como arte por sobre la literatura como manifestación del uso lingüístico. Por otra parte, hay quienes piensan que la literatura es la forma de expresión en que el lenguaje se despliega en su mayor potencial significativo y creador, y por tanto, los mejores textos para aprender el uso de la lengua serían los literarios. En tanto, en la práctica educativa, encontramos una tendencia a reducir el tratamiento de la literatura a competencias lingüísticas parciales que pierden de vista la obra en su conjunto como portadora y generadora de significados.

La relación de la literatura con la competencia comunicativa depende de lo que queramos que los estudiantes aprendan. Si lo que queremos es que redacten una solicitud o entiendan un instructivo, probablemente la literatura pueda ser prescindible. Pero si queremos que sean lectores analíticos no solo de los textos escritos, sino de los discursos sociales, culturales, históricos, el estudio de la literatura es indispensable, pues nos enfrenta a la realidad desde la libertad creadora e inquisitiva del arte.

Las obras literarias, como objetos lingüísticos, ofrecen la ocasión de relacionarse con los diferentes aspectos de la lengua. Entendida la literatura en este sentido, se deduce que existe una relación ineludible entre lengua y literatura, en tanto la literatura se funda en el lenguaje y en tanto tal ninguna posibilidad o recurso del lenguaje le son ajenos. Tanto es así, que no se ha encontrado ningún recurso lingüístico exclusivo de la literatura.

Por otra parte, la literatura tiende a distanciarse de la lengua en su uso comunicativo práctico y a acercarse a otros dominios artísticos. Frente a esta problemática, Antonio Mendoza Fillola (2008), desde la didáctica de la literatura, propugna el desarrollo de la competencia literaria, entendida como un tipo de competencia comunicativa, lo que amplía la taxonomía. En relación con la lectura literaria, el objetivo esencial, según el autor, es "aprender a interpretar y aprender a valorar y apreciar las creaciones de signo estético-literario" (MENDOZA, 2008).

Un aspecto que genera conflicto entre literatura y competencia comunicativa es el concepto de acto comunicativo asociado a la idea de intercambio: "todo acto comunicativo entre dos o más personas en cualquier situación de intercambio está regido por reglas de interacción social [competencias]" (FISHMAN, 1970 apud PILLEUX, 2001). En literatura, es problemático aplicar el concepto de acto comunicativo entendido como intercambio, si pensamos en el acto creativo como la situación en que un sujeto produce un textoobjeto artístico frente a la página en blanco. 
A esto podría objetarse la idea de que existe, aun en ese acto monológico, un destinatario potencial, ya se trate del lector modelo, el lector implícito o lector real, en cuyo caso es un acto diferido, esto es, con distancia temporal entre el sujeto real y aquello que enuncia. Si bien también podría aceptarse que todo texto en tanto discurso es una puesta en escena de un enunciador y un mensaje (CHARAUDEAU apud ALVAREZ, 2001), así como que en todo discurso escrito hay diferimiento, en la literatura como ficción la relación del autor con la realidad no funciona en términos de correspondencia directa entre la intención del autor y el mensaje.

Lo anterior tiene sentido si pensamos en observaciones recurrentes por parte de escritores, como que les resulta difícil interpretar su propia obra, que su creación adquiere independencia del autor o que les complica adjudicarle un sentido determinado a algún aspecto de sus creaciones. En el texto funcional, el emisor construye una imagen, pero una imagen de sí mismo, que lo representa; esto, aun en los casos en que se recurre a la ficción, como en la publicidad. En la ficción literaria, el autor construye un emisor que puede o no coincidir con él. De ello se deriva que la identidad del emisor no se corresponde de manera equivalente con la identidad del autor, y que, por lo tanto, el autor no es el llamado a dilucidar los sentidos de su obra; el autor no está obligado a ser fiel a la realidad empírica y tampoco puede cuestionarse la verdad o falsedad de su obra en ese sentido.

Con esto no defiendo la muerte del autor. Me parece válido y de posible interés lo que pueda decir el autor sobre la gestación de su obra, de los significados que le otorga como lector actual y de las intenciones que tuvo en el momento de producción. Todo esto puede aportar a la comprensión del texto, aunque con diferencias según la obra. El escritor asume la independencia de su creación respecto de sí mismo y de la realidad empírica.

Lo que me interesa destacar es que si se considera la literatura como acto comunicativo, es necesario entenderlo con sus énfasis específicos y considerando su carácter artístico. Esto tiene que ver con la primacía de la función estética o principio artístico y la polisemia o apertura a la significación. En este sentido, al decir de Mansilla (2003), la literatura no tiene como condición sine qua non asegurar la comunicabilidad del mensaje anulando o transparentando la connotación. Estas consideraciones tienen relevancia desde una perspectiva didáctica, puesto que las características de los textos inciden en la actividad de lectura. Así, no toda estrategia o técnica planteada en general es provechosa para la lectura literaria.

A continuación, muestro cómo es posible abordar la literatura en relación con la competencia comunicativa. Recurro intencionalmente a obras literarias sin distinción de edad ni nivel de escolaridad, de modo a evidenciar si es o no factible desarrollar aspectos de las competencias en distintos niveles. En algunos casos, se trata de obras infantiles; en otros, aunque sean textos para adultos, son lecturas adecuadas para jóvenes escolares.

\section{Lo que dicen y no dicen las palabras: lo léxico-semántico}

El contacto con la literatura nos vuelve más perceptivos a la variedad léxica, al hecho, por ejemplo, de que los sinónimos como palabras que significan lo mismo se dan de manera escasa y que entonces importa y mucho la selección de las palabras. En el poema Sebastián Acevedo, de Gonzalo Rojas (1988), encontramos la palabra inmolado de manera recurrente en referencia a Acevedo. No se cambia la palabra por un sinónimo porque ninguna de las palabras que el diccionario da como sinónimas significa lo mismo que inmolado en su matiz diferencial: sacrificar algo por una causa o por alguien ${ }^{2}$; es eso precisamente lo que hace Acevedo cuando

2- El Diccionario de la lengua española de la Real Academia Española lo consigna como sigue en su tercera acepción: "3. prnl. Dar la vida, la hacienda, el reposo, etc., en provecho u honor de alguien o algo". 
se inmola en la plaza de Concepción para que la CNI (Central Nacional de Informaciones) entregara a sus hijos detenidos durante la dictadura civil-militar presidida por Pinochet. El poema contiene la expresión anafórica solo veo al inmolado, la que, repetida al final de cada párrafo, expresa la conmoción emocional del sujeto poético y produce el efecto de instalar la imagen en la retina del lector.

Es interesante reparar en cómo con el uso de ciertas palabras precisamos, acotamos o ampliamos el significado. A través del léxico podemos evidenciar la intención artística del texto literario, en que las palabras se seleccionan y se disponen de cierta manera. Así, por ejemplo, en El oso que no lo era, de Franz Tashlin (2011), no da lo mismo decir y pasó el invierno que decir y pasó el largo y frío invierno, adjetivos que tienen relación con el hábitat y características del oso, pero también con la forma como la narración produce el efecto de paso del tiempo a través de la diégesis o discurso del narrador. Ese paso del tiempo hace más verosímil que mientras el oso duerma ocurran muchos cambios en el lugar: el bosque es invadido por las industrias.

La polisemia de las palabras y el juego con la ambigüedad también podemos estudiarlas en la literatura. Papelucho perdido, de Marcela Paz, llama la atención sobre el lenguaje y las connotaciones de las palabras. En Papelucho perdido, el protagonista dice "Soy un perdido y la Jimena del Carmen, ídem, y lo peor es que nadie nos busca (...) Tampoco buscaron a la tía Ema, sino que dijeron siempre: la Ema es una perdida, y se acabó el cuento" (1995, p. 3). En este caso, la autora intenciona la ambigüedad como recurso para dar verosimilitud al discurso del niño (Papelucho aplica solo un significado para el significante, pues no conoce la acepción con que se la usa en referencia a la tía). También podemos leer otras connotaciones si relacionamos la palabra con la historia y el personaje. Papelucho se pierde físicamente, pero esa pérdida conlleva connotaciones afectivas: la distancia de la madre y del padre. Papelucho es un personaje desacomodado socialmente; algo sugiere en ese sentido el soy un perdido, y no estoy perdido.

En otro nivel, también podemos leer significados simbólicos de palabras. Pensemos, por ejemplo, en la palabra jardín, la que adquiere significados particulares en El jardín secreto, de Hodgson Burnett (2005), en donde podría significar el paso del tiempo, la vida y la muerte, el renacimiento espiritual, la maduración personal. El jardín es un motivo presente en el Génesis, intertexto insoslayable. Otro ejemplo: el anillo, en El señor de los anillos, de J.R. Tolkien, en donde el anillo simboliza el poder. El significado simbólico del anillo no es particular de Tolkien, sino que lo encontramos a lo largo de la historia, hasta hoy en día; por ejemplo, en la autoridad papal y en el matrimonio, aunque con otro significado en este caso. En Tolkien, el anillo puede constituirse por momentos en protección a través de su poder mágico; es usado para hacer el bien, pero, en otros momentos, puede ser una fuente de degradación o de despotismo y violencia, como efectivamente, ocurre con el poder.

En la literatura también encontramos neologismos, a partir de los que podemos reflexionar sobre el lenguaje y su relación con la literatura. Todo recurso literario, en tanto se constituye en y por el lenguaje, es recurso lingüístico, es decir, es una posibilidad que ofrece el lenguaje en general. Ahora bien, el mecanismo tiene sus matices diferenciales en el uso: en textos literarios, el neologismo suele circunscribirse al contexto semántico (textual) de la obra y puede crear palabras que no respondan necesariamente a relaciones semánticas con palabras previas.

Un ejemplo de neologismo lo constituye el título que Juan José Arreola (2007) da a su libro de relatos, Confabulario; es un juego lingüístico y al mismo tiempo un mecanismo semántico que le permite al autor construir significado. En la palabra confabulario se imbrican dos conceptos: fabulario (repertorio de fábulas) y confabular (ponerse de acuerdo para emprender algún plan, generalmente ilícito). Así, estos dos significados 
se conjugan para nominar y caracterizar al conjunto de textos: algo tienen de fabulario y algo tienen de confabulación. Pasamos así de reconocer significados de palabras a establecer asociaciones entre esas palabras y diferentes aspectos del texto. Vemos que la palabra confabulación adquiere nuevas connotaciones. En este caso, podríamos interpretar que el autor, a través del texto, confabula con el lector, ambos son cómplices en subvertir la realidad para mirarla desde otro ángulo, lo que nos lleva a preguntarnos por las formas de subversión que podemos identificar en el texto, tanto subversiones formales como de ideas relativas a la sociedad. Otro ejemplo de neologismo literario conocido es Altazor, título de una obra de Vicente Huidobro (2012); además, puede decirse que es uno de los principales recursos lingüísticos del texto, el que se entiende desde la poética creacionista de Huidobro.

\section{Un texto, varios textos}

La tipología textual no ha tenido un tratamiento didáctico productivo para el aprendizaje en el contexto escolar. Clasificar los textos con criterio homogéneo, sin vincularlos con otras características de la obra, no parece ser muy provechoso. Los textos suelen ser heterogéneos (ADAM; LORDA, 1999); pueden contener una variedad de secuencias correspondientes a distintos tipos de textos.

Los textos literarios, particularmente los narrativos, contienen diversas formas textuales, diversas secuencias tipo: descripciones, diálogo, narración, argumentación, explicación. En este sentido, los profesores, al analizar una obra, pueden llamar la atención sobre este aspecto para que los alumnos identifiquen tipos de secuencias, preguntándose por la función que cumplen en el texto y de qué manera aportan a los sentidos de la obra y al ritmo. De aquí podría avanzarse a una lectura que desarrolle la capacidad de valorar un texto a partir de nociones de tipos de textos que no se queden en las superestructuras o esqueletos, sino que consideren también las particularidades del lenguaje de cada obra y cómo aportan al conjunto del texto.

Así, podemos hacer que los lectores observen que en una obra narrativa no solo se cuenta algo, sino que también se describe o los personajes interactúan entre sí por medio del diálogo. En esta línea, podemos comparar textos con diálogo y sin diálogo, textos con mayor o menor presencia de descripciones o comparar obras que tengan un referente común pero que se aborden desde formas textuales y discursivas diferentes. Como ejemplo de esto último, podemos leer un texto expositivo sobre el ciclo del agua y leer el cuento Las nieves eternas (Sub sole, de Baldomero Lillo).

Como lo muestran Adam y Lorda (1999) en el caso de los mitos, encontramos versiones que se enmarcan en textos explicativos, mientras que otras, del mismo mito, corresponden a textos narrativos. El libro de Mercedes Franco (2007), Diccionario de fantasmas, misterios y leyendas de Venezuela, resulta particularmente interesante por su estructura externa e interna. Los textos se organizan según el formato de diccionario; sin embargo, internamente existe diversidad de formas textuales; encontramos secuencias descriptivas, narrativas, explicativas. El criterio que define la estructura no responde tanto a un formato previo como a lo que el concepto a definir demanda, así como a la comprensión y la amenidad de la lectura.

También podemos derivar hacia la reflexión sobre la ficción literaria en el sentido de reconocer el aporte de lo literario en el tratamiento de un tema, hecho histórico, fenómeno cultural, conocimiento científico. Por ejemplo, en relación con un hecho histórico como la matanza en la Escuela Santa María de Iquique ${ }^{3}$, podemos leer textos historiográficos, como Los que van a morir te saludan: historia de una masacre, de Eduardo Devés (2002), y

3- Masacre de los mineros del salitre y sus familias, ocurrida en la Escuela Santa María de la ciudad de Iquique, Chile, en 1907, a raíz de la movilización sindical y huelga obrera para demandar mejoras de las míseras y opresivas condiciones laborales que padecían. 
la novela Santa María de las flores negras, de Rivera Letelier (2002), de modo que los alumnos comprendan la ficción novelesca como un espacio en que el escritor construye un mundo con el lenguaje, mundo que no se rige por el criterio de verdad versus falsedad, sino que se relaciona con la realidad desde la libertad imaginativa del arte.

Desde un enfoque interdisciplinario, podemos leer con los estudiantes ensayos científicos, como Brevísima historia del tiempo, de Stephen Hawking, y obras de literatura fantástica, como algunos cuentos de Borges y Cortázar, y complementar con una perspectiva más existencial, subjetiva y social, como la novela Momo, Michael Ende, la que, a través de la fantasía alegórica, nos apela con respecto a la forma paradójica de relacionarnos con el tiempo en las sociedades regidas por la cultura mercantilista, sintetizada en la frase time is money: no perder tiempo (en tanto este es producción y dinero) redunda en la pérdida del tiempo vital.

Stephen Hawking y Lucy Hawking (2008, 2009) también han escrito novelas para niños La clave secreta del universo y El tesoro cósmico - las que acercan al conocimiento del cosmos y de nuestro planeta a través de textos que conjugan la narración con textos explicativos sobre temas científicos, con adecuada legibilidad lingüística para el nivel de lectores infantojuveniles. Estas obras se caracterizan por una multisemiosis que combina los diferentes sistemas: verbal, gráfico, matemático y tipográfico. En los libros encontramos la historia narrada y paratextos como fotografías del cosmos, cuadros con información explicativa, diagramas; además, en el texto diegético, o de la historia, también existe diversidad textual, como el libro científico de Eric. Este personaje es el padre de Anni, y quien escribe el texto para que su hija y su amiguito puedan comprender el cosmos y la ciencia que lo estudia.

Es interesante considerar también el cine, que puede favorecer el acercamiento posterior a obras literarias de difícil lectura para la edad de los estudiantes, o funcionar como complemento de la lectura de obras de literatura infantil y juvenil. A la vez, el cine tiene valor en sí mismo, pues permite desarrollar la apreciación estética y la reflexión si implementamos actividades orientadas a ello.

De esta manera, la literatura nos acerca a la comprensión de ciertos conceptos y a la problematización de la experiencia. Así, no solo contrastamos textos literarios con textos de otros dominios, sino que también los hacemos dialogar en la fluidez del conocimiento.

\section{Géneros discursivos: múltiples} voces

Así como la literatura es diversa desde el punto de vista de los tipos de textos, también lo es en lo que respecta a géneros discursivos. La obras literarias, como lo hizo ver Bajtín (2002), pueden contener la heteroglosia social, es decir, plasmar la diversidad discursiva, la que se verifica en grados diferentes en los textos. Los géneros discursivos se conforman como tales en base a características retóricas que consideran el uso de cierto léxico, formas gramaticales, fórmulas lingüísticas, registros de lengua, además de las superestructuras textuales. Según recurrencias de algunos de estos aspectos, una obra literaria podemos analizarla como perteneciente a un género, a un subgénero y como espacio en donde confluyen múltiples posibles géneros, de diversos ámbitos y variedades lingüísticas.

Por tanto, a partir de un texto, podríamos intencionar que los estudiantes se percataran de esta confluencia de discursos, entendiéndolos no como representación mimética de la realidad sino como acto creativo en que se selecciona, modifica y recontextualiza, con todo lo cual se crea un universo con sentidos. Incorporar otros géneros es una forma de intertextualidad. Un género discursivo podría ingresar en registro directo o irónico, serio o humorístico. Esta diferencia puede ser relevante al momento de interpretar el texto: pensar en qué discursos 
ingresan y de qué manera. Básicamente, podríamos identificar dos formas en que se incorporan a la obra: impregnando el conjunto del texto y afectando la macroestructura, o bien, insertándose parcialmente en distintos momentos de la obra. En el primer caso, tenemos textos con géneros apócrifos, es decir, una obra literaria escrita a modo de. Por ejemplo, a modo de diario de vida, como Papelucho perdido, de Marcela Paz (1995); Nuestras sombras, de María Teresa Budge (1996), o la mayor parte de El niño que enloqueció de amor, de Eduardo Barrios (2004); o a modo de género epistolar, en que la historia se narra a través de cartas, como Papito piernas largas, de Jean Webster (2001).

A partir de lo anterior, es importante hacer notar la diferencia entre ficción literaria y géneros que ingresan a la obra como recursos de la ficción, pues puede ocurrir que los lectores se queden con la impresión de que están en presencia de un género no ficcional, es decir, pueden creer que se trata, por ejemplo, de un diario de vida y no de una novela (y ocurre, lo he comprobado en mis clases). Por esto es importante que los lectores reparen en los indicios del texto y de los paratextos que permiten reconocer el género y el carácter ficcional o no ficcional de la obra. Algunas preguntas que podemos plantearnos al momento de considerar este aspecto en la lectura son: ¿por qué los identificamos como un género en particular?, ¿qué los caracteriza como tales?, ¿con qué ámbitos y sujetos los identificamos?, ¿qué sentido tienen en la obra?

En Historias de cronopios y de famas, de Julio Cortázar (2003), encontramos algunos textos a los que el autor denomina instrucciones, que toman prestadas características lingüísticas del texto instructivo sin llegar a serlo. Esto nos muestra la esencia cortazariana de la función crítica de la literatura: provocar a través del lenguaje, la ficción y el arte. Las instrucciones de Cortázar le hacen una jugarreta a este género, con lo que la crítica social implícita relativa a una sociedad encorsetada por normas, rutinas $\mathrm{y}$ falta de libertad creadora coincide con la subversión del género instructivo. Así, en estos textos el contenido tiene su correlato en el tratamiento discursivo.

En el libro álbum Willy el tímido, de Anthony Browne (2009), por ejemplo, se inserta un texto reconocible como aviso publicitario, el que considera lo lingüístico y lo visual (semeja un recorte de diario); además, el aviso adquiere un significado particular en el contexto de la obra: pierde su carácter funcional y adquiere nuevos sentidos. Si lo relacionamos con la historia, y especialmente con el final, se revela la ironía, pues la obra incorpora el discurso publicitario para subvertirlo. De esta manera, el texto contribuye de forma virtual al aprendizaje de niñas y niños, a través de la experiencia del personaje - como plantea Bettelheim (2010). Por ello, con lectores pequeños o primeros lectores, no es necesario que la profesora dé un discurso sobre las cuestionables premisas y recursos disuasivos de la publicidad. Sí es atendible que obtenga información de cómo los niños entienden la historia y que dirija la atención hacia algunos aspectos específicos para formarlos como lectores reflexivos. En el caso de esta obra, es fundamental que los niños infieran que Willy no cambió interiormente, solo lo hizo físicamente.

Podemos hacer que los alumnos se percaten del sentido del intertexto publicitario en esta obra con preguntas para el diálogo: ¿han escuchado algo como lo que dice este aviso?, ¿por qué creen que Willy hizo lo que decía el aviso comercial?, ¿le sirvió hacer lo que decía el aviso para superar su timidez? Luego los alumnos podrían comparar la experiencia del protagonista de esta historia con personajes como Pulgarcito y Pulgarcita, quienes no cambian su tamaño pero son capaces de enfrentar y superar situaciones adversas.

Browne (2009) muestra en Willy el tímido que es plausible concebir obras literarias infantiles en que no haya final feliz y que, sin embargo, pueden ser efectivas en términos de satisfacer las necesidades psicológicas del niño, algo que ya había logrado Roald Dahl. El lector infantil puede aceptar una historia 
sin happy end, pero si no es un final trágico. El final de la historia de Willy, aun cuando no sea feliz, añade algo de humor, el que también se produce en otros momentos del texto. Esta historia se aleja del cuento infantil tradicional, en que el protagonista, héroe o heroína, sortea una serie de obstáculos para conseguir su objetivo y finalmente es recompensado. Sin duda, se hacen necesarios estudios que indaguen en la recepción lectoliteraria de los diferentes géneros, formatos y estilos de las obras de literatura infantil.

En ciertas obras, se observa la presencia de otros géneros o subgéneros literarios y de frases hechas. En el relato Un pajarito me contó, de Ana María Machado (2011), la narración se teje entre acercamientos y distanciamientos con respecto al relato maravilloso. Para una comprensión de los guiños de la autora, el texto supone un lector conocedor de ese tipo de relato. Parte de la gracia del texto radica en las acotaciones del narrador, con humor irónico, a algunas fórmulas de los cuentos, las que terminan por subvertirse en esta obra de Machado: "Su majestad el rey manda avisar que dará un tesoro a quien resuelva el problema que amenaza con matar el reino. Esto, también, ya se sabe. Siempre es así en los cuentos" (2011, p. 13,14). Los caballeros son aquí personajes secundarios, a quien el rey convoca para que resuelvan el problema desconocido, pero no logran dar con el enigma y terminan por convertirse ellos en problema al saquear las riquezas del lugar. El discurso exhibe una función metatextual: refiere la ficcionalidad cuando el narrador reconoce su relato como cuento, y cuando el rey pregunta a los niños si ellos son los personajes del cuento Juan y María, en alusión intertextual a Hansel y Gretel. En este punto, el relato ofrece la posibilidad de conectar con obras que reescriben cuentos infantiles tradicionales.

El relato puede leerse como una alegoría del contexto social y político brasileño y latinoamericano. La frase un pajarito me contó nos envía a la expresión coloquial que usamos para referirnos a algo sabido por boca de otro(s) y cuya fuente no queremos revelar. Esta expresión tiene especial sentido en el contexto histórico: la obra fue publicada por primera vez en 1983, cuando todavía regía la dictadura militar en Brasil. Como recurso del maravilloso, la frase se vuelve motivo literario: la narración es posible porque un pajarito, que aparece como personaje, verdaderamente le contó la historia al narrador. Así, al poner atención a estos aspectos, el cuento permite reflexionar sobre la ficción, los géneros y cómo la literatura dialoga con otros tipos de textos literarios y con expresiones coloquiales. $\mathrm{Al}$ mismo tiempo, es posible relacionar el cuento con la realidad social y la riqueza natural de Latinoamérica, así como con el sentido de escuchar a las personas y de buscar soluciones en conjunto a problemas comunes.

\section{Comunicarse y entender el mundo: sociocognición y competencia cultural}

Sabemos que todo texto es escrito por alguien, y que ese alguien escribe desde algún lugar. Por las características de un texto, podríamos conocer algo de su autor, ya que este, al pertenecer a un contexto determinado, participa de esquemas que le son dados por la cultura, lo que incide en la forma de representación de mundo, de interpretación y valoración de él. En este sentido, podemos observar cómo el discurso refleja ideas transmitidas culturalmente. Pero también, en muchas ocasiones, el propio ejercicio escritural literario permite que el sujeto que escribe experimente contradicciones, se objetive, se cuestione, desestabilizando esquemas ideológicos.

Ser competente sociocognitivamente equivaldría a compartir (no en el sentido de estar de acuerdo) esquemas o referentes culturales significativos para entender y producir mensajes.

Todos tenemos un cúmulo de conocimientos que construimos durante nuestra vida, durante el proceso de socialización, 
conocemos lo que pasa en nuestra cultura. (VAN DIJK, 1994, p. 9)

La literatura contribuye a ello al ampliar nuestro conocimiento cultural, en cuanto a mundo objetivo y a formas de entender las interacciones en él. Según Van Dijk, "el discurso y la comunicación tendrán diferentes propiedades en las diferentes culturas (...) los actos de habla y las interacciones están íntimamente relacionados con los contextos y marcos sociales" (1996, p. 112), en los que la ideología determina la selección de normas y valores.

Esta competencia funciona intimamente ligada a la competencia cultural, la que podría sintetizarse como conocimiento cultural que permite entenderse y actuar en una comunidad hablante, y que involucra valores, creencias, actitudes y comportamientos sociales. Como señala De Santiago (2010), además de la comprensión lingüística

(...) también debemos extraer del contexto las reglas culturales, las costumbres $\mathrm{y}$ 5hábitos sociales que son igualmente necesarias para interpretar un mensaje $\mathrm{y}$ no caer en constantes interferencias comunicativas. El problema es que esos datos, en numerosísimas ocasiones faltan. (2010, p. 113-114)

Un ejemplo de fallo en la competencia es la frase que el presidente Sebastián Piñera estampó en el libro de visitas del palacio presidencial de Alemania, como corolario de su estadía: Deutshland über alles (Alemania sobre todo). La frase comporta una connotación nazi para los alemanes; por esto la sacaron del himno nacional. Cualquier manifestación de adherencia al nazismo es considerada inaceptable en el discurso político público de ese país. Es evidente que el emisor ignoraba algo: la asociación de la frase con el régimen nazi o la implicancia política de la frase para la sociedad alemana. Este caso nos muestra la importancia de compartir ciertos valores o conocimiento dados por la cultura para entenderse, lo que a menudo trasciende la competencia lingüística de una lengua e involucra a las personas como seres sociales en interacción con la(s) cultura(s).

Una pregunta que podríamos hacernos y plantear a los lectores que formamos es si podemos inferir algunos rasgos de identidad del autor (de género, nacionalidad, política, etc.). Esto podría conseguirse inductiva o deductivamente: los estudiantes investigan previamente acerca del escritor y luego relacionan algunos aspectos con el texto; o bien que primero lean la obra, infieran posibles rasgos de identidad cultural y comparen posteriormente con información aportada por la profesora o investigada por ellos mismos. Esto dependerá de la obra en particular, de la cantidad y cualidades de los indicios del texto y del conocimiento previo de los estudiantes sobre el autor y la cultura a la que pertenece.

La literatura, en muchas ocasiones, objetiva y cuestiona algunos esquemas. En otras, el autor asimila esquemas culturales de los que participa. Esto lo podemos apreciar, por ejemplo, en la diferencia de perspectiva que puede adoptar un mismo relato mítico en diferentes versiones: cuando lo cuenta una persona que participa de la comunidad de origen y de la cosmovisión presente en la historia y cuando se evidencia que el autor no participa de ella y se distancia. La literatura latinoamericana resulta especialmente interesante en cuanto a la presencia de esquemas sociocognitivos provenientes de distintas fuentes culturales que dialogan y se relacionan conflictivamente.

En algunas obras, ciertas visiones implícitas en el discurso se relacionan de manera problemática. Existen textos que socavan ideologías e imaginarios culturales a través de la ironía y del contraste entre visiones de mundo. Un ejemplo de ello es el cuento $E l$ eclipse, de Augusto Monterroso (1995), en que se ficcionaliza el encuentro y desencuentro entre españoles y mayas, y se echa por tierra la supuesta superioridad del conquistador. También los textos de Eduardo Galeano (2013 y 2006) 
subvierten esquemas culturales relativos a las versiones y visiones oficiales de la Historia, así como a los estereotipos de género, y reflexionan sobre las connotaciones ideológicas presentes en el uso de la lengua. Destaco Memoria del fuego. Los nacimientos y El libro de los abrazos.

Clayton Bess (1997), en su novela Cuento negro para una negra noche, presenta dos visiones religiosas y culturales distintas, representadas en la historia y encarnadas por los personajes de Ma y Ma Grande. Aun cuando pertenecen a un mismo contexto geográfico, son de generaciones distintas, por lo que Ma ha ido a la escuela, en donde ha accedido a la educación y por tanto a la cultura occidental, especialmente se destaca que ha aprendido a leer y ha conocido la Biblia y la religión cristiana. Esto determina sus visiones, las que generan conflictos entre ellas (CARRANZA, 2004).

El narrador, en la primera parte de la novela de Bess, juega con la indeterminación del verosímil; crea una atmósfera de misterio que sugiere un posible relato de fantasía y terror, con referencias al mal y a espíritus del imaginario africano. Sin embargo, en el desarrollo del relato, se nos revela que el mal del que nos habla la obra no es sobrenatural. De esta manera, el autor implícito se nos presenta distanciado del esquema religioso de Ma Grande, pues el aura de misterio de los hechos se diluye tras explicarse racionalmente. $\mathrm{Al}$ mismo tiempo, es posible leer cierta simpatía por el cristianismo en la gran ponderación del personaje de la madre. Pero, por otra parte, también encontramos una visión crítica de otros personajes cristianos. Esto nos indica que los esquemas culturales no son los que determinan taxativamente la axiología de esta obra. La valoración de los personajes más bien responde al comportamiento y a la actitud en la relación con los otros. De esta manera, la obra en su conjunto se caracteriza por una perspectiva ideológica abierta que contribuye a formar sujetos críticos y tolerantes a la diversidad cultural.

\section{Consideraciones finales}

Luego del análisis, es posible concluir que la literatura no es ajena a la competencia comunicativa. La lectura y la escritura literarias, en tanto se fundan en textos $\mathrm{y}$, por ende, en la lengua, comparten con ella conocimientos y habilidades. No obstante, estos han de estar en función de las características de lo literario. De esta manera, los estudiantes desarrollarán la comprensión lectoliteraria sacando provecho de sus posibilidades, lo que, en definitiva, redundará en la formación de lectores más agudos, atentos y reflexivos.

La literatura puede constituirse en una instancia privilegiada en la enseñanza de la lectura. Si bien nadie niega la pertinencia de formar buenos usuarios de la lengua, también es aconsejable que la literatura no se diluya en unas cuantas estrategias y habilidades genéricas de comprensión lectora. Como he mostrado en este trabajo, la literatura también puede aportar al desarrollo de la competencia comunicativa, pero solo tiene sentido que lo haga considerando sus formas de expresión, sus conexiones con la realidad y con los lectores, y la construcción de sentido.

Finalmente, lo más importante no es enseñar competencias lingüísticas a través de la literatura, sino mediar en la comprensión del aporte de la literatura en tanto tal y en cómo podemos sacar provecho de ella. Por este camino, el aprendizaje literario no se sintetiza en un índice numérico de comprensión lectora ni se reduce a la eficacia comunicacional, sino que decanta en el tiempo, constituye materia de conocimiento e interesa para la formación de la persona no solo en tanto hablante sino también como sujeto y ciudadano. 


\section{Referencias}

ADAM, Jean Michelle; LORDA, Clara. Lingüística de los textos narrativos. Barcelona: Ariel, 1999.

ALVAREZ, Gerardo. Textos y discursos: introducción a la lingüística del texto. Concepción, Universidad de Concepción, 2001.

ARREOLA, Juan José. Confabulario. 3. ed. México: FCE, 2007.

BAJTín, Mijaíl. Estética de la creación verbal. Buenos Aires: Siglo XXI, 2002. Traducción de Tatiana Bubnova.

BARRIOS, Eduardo. El niño que enloqueció de amor. Santiago: Andrés Bello, 2004.

BESS, Clayton. Cuento negro para una negra noche. Santafé de Bogotá, D.C.: FCE, 1997. Traducción de Rafael Segovia Albán.

BETTELHEIM, Bruno. Psicoanálisis de los cuentos de hadas. Barcelona: Crítica, 2010. (Ares y mares). Traducción de Silvia Furió. BROWNE, Anthony. Willy el tímido. México: FCE, 2009. Traducción de Carmen Esteva.

BUDGE, María Teresa. Nuestras sombras. 6. ed. Santiago: Andrés Bello, 1996.

CARRANZA, Marcela. Cuento negro para una negra noche. Imaginaria, Buenos Aires, n. 124, 2004. Disponible en: <http://www. imaginaria.com.ar/ 12/4/cuentonegro.htm> Acceso en: 20 sept. 2012.

CHILE. MINEDUC. Lenguaje y comunicación: educación básica. Bases Curriculares, 2012. Disponible en: <http://www.mineduc. cl/index5_int.php?id_portal=47\&id_contenido=17116\&id_seccion=3264\&c=1 >. Acceso en: 16 mayo. 2012.

CHILE. MINEDUC. Actualización curricular: lenguaje y comunicación. 2009. Disponible en: <http://www.mineduc.cl/index5_int. php?id_portal=47\&id_contenido $=17116 \& i d \_$. . Acceso en: 10 jun. 2010.

COLOMER, Teresa. Andar entre libros. México: FCE, 2010.

CORTÁZAR, Julio. Historias de cronopios y de famas. In: CORTÁZAR, Julio. Cuentos completos. Buenos Aires: Alfaguara, 2003. v. 1.

DE SANTIAGO UERVÓS, Javier. La competencia cultural en la competencia comunicativa: hacia una comunicación intercultural con menos interferencia. Marcoele. Revista de Didáctica Español Lengua Extranjera, n. 11, p. 113-130, 2010. Disponible en: <http://marcoele.com/monograficos/lenguas-de-especialidad/>. Acceso en: 12 mar. 2013.

DEVÉS, Eduardo. Los que van a morir te saludan: historia de una masacre: Escuela Santa María de Iquique. 4. ed. Santiago: Lom, 2002.

DONOSO Díaz, Sebastián. Reforma y política educacional en chile 1990-2004: el neoliberalismo en crisis. Estudios Pedagógicos, Valdivia, v. 1, n. 31, p. 113-135, 2005.

FRANCO, Mercedes. Diccionario de fantasmas, leyendas y misterios de Venezuela. Caracas: CEC, 2007.

GALEANO, Eduardo. El libro de los abrazos. Buenos Aires: Catálogos, 2006.

GALEANO, Eduardo. Memoria del fuego: los nacimientos. Buenos Aires: Siglo XXI, 2013.

HAWKING, Stephen; HAWKING, Lucy. Brevísima historia del tiempo. Barccelona: Crítica, 2010. Traducción de David Jou.

HAWKING, Stephen; HAWKING, Lucy. La clave secreta del universo. Buenos Aires: Sudamericana, 2008. Traducción de Laura Martín de Dios.

HAWKING, Stephen; HAWKING, Lucy. El tesoro cósmico. Buenos Aires: Sudamericana, 2009. Traducción de Silvina Pons Pradilla. HODGSON BURNETT, Frances. El jardín secreto. Santiago de Chile: Andrés Bello, 2005. Traducción María Decombe. 
HYMES, Dell. On communicative competence. In: PRIDE, J.B.; HOLMES, J. (Orgs.). Sociolinguistic. Londres: Penguin Books, 1972. p. 269-293.

HUIDOBRO, Vicente. Altazor. Santiago: Universitaria, 2012.

LILLO, Baldomero. Sub sole. Santiago: Andrés Bello, 1999.

MACHADO, Ana María. Un pajarito me contó. México: FCE, 2011.Traducción de Mónica Mansour.

MANSILLA, Sergio. La enseñanza de la literatura como práctica de liberación. Santiago: Cuarto Propio, 2003.

MENDOZA FILLOLA, Antonio. La educación literaria: bases para la formación lectoliteraria. 2008. Disponible en: <http://www. cervantesvirtual.com/obra-visor/la-educacin-literaria-bases-para-la-formacin-de-la-competencia-lectoliteraria-/html/01e1d59a82b2-11df-acc7-002185ce6064_2.htm|\#__0_>. Acceso en: 17 mayo 2011.

MONTERROSO, Augusto. El eclipse y otros cuentos. Madrid: Alianza, 1995.

MUNITA, Felipe. Literatura y escuela: un diálogo posible. Valdivia: Kultrún, 2010.

PARODI, Giovanni. Multisemiosis y lingüística de corpus: artefactos (multi)semióticos en los textos de seis disciplinas en el corpus. RLA, Concepción, v. 2, n. 48, p. 33-70, 2010.

PAZ, Marcela. Papelucho perdido. Santiago de Chile: Universitaria, 1995.

PILLEUX, Mauricio. Competencia comunicativa y análisis del discurso. Estudios Filológicos, Valdivia, n. 3, p. 143-152, 2001.

REAL ACADEMIA DE LA LENGUA ESPAÑOLA. Diccionario de la lengua española. 22. ed., 2001. Disponible en: <http://lema.rae. es/drae/?val=inmolar>. Acceso en: 25 nov. 2013.

RIVERA LETELIER, Hernán. Santa María de las Flores Negras. Santiago: Seix Barral, 2002.

ROJAS, Gonzalo. Sebastián Acevedo. In: ROJAS, Gonzalo. Materia de testamento. Madrid: Hiperión, 1988.

TASHLIN, Franz. El oso que no lo era. 11 ed. Santiago de Chile: Alfaguara, 2011. Traducción de Santiago Lodano.

TOLKIEN, J. R. R. El señor de los anillos: la comunidad del anillo. Barcelona: Minotauro, 2001. Traducción de Luis Domènech.

VAN DIJK, Teun. Estructura discursiva y cognición social. 1994. Disponible en: <http://reocities.com/Athens/Troy/3860/ vandijk_edcs.html>. Acceso en: 20 ago. 2012.

VAN DIJK, Teun. Las estructuras y funciones del discurso. 10. ed. México: Siglo XXI, 1996.

WEBSTER, Jean. Papito piernas largas. 22. ed. Santiago de Chile: Universitaria, 2001. Traducción de Isabel Wetchlotz.

Recebido en: 08.06.2013

Aprobado en: 02.10.2013

Ximena Troncoso Araos es doctora en Literatura Latinoamericana, académica en la Facultad de Educación de la Universidad Católica del Maule. 